\title{
Effects of Autogenic Drainage in Patients with Abdominal Surgery
}

\author{
FATEN A. HAMZA, Ph.D. \\ The Department Physical Therapy for Cardiovascular-Respiratory Disorders and Geriatrics, Faculty of Physical Therapy, \\ Delta University for Science and Technology, Egypt
}

\begin{abstract}
Background: Surgery has become an important part of global health care, estimated to about 234 million patients operated yearly. Surgery and general anesthesia directly affects the respiratory system. Surgeries alter postoperative pulmonary function causes impairment of lungs volume such as total lung capacity, vital capacity and tidal volume and can develop post pulmonary complications.
\end{abstract}

Aim of Study: Is to study the effect of autogenic drainage (AD) breathing technique in abdominal surgery patients to prevent those complications.

Patients and Methods: Thirty participants who underwent abdominal surgeries with age 30-60 years were included in the study for one week of intervention. Total seven sessions was given in a week and pre and post readings were taken by using inch tape at Axillary level, inspiratory capacity was taken with help of incentive spirometer (Helios 401) and peak expiratory flow rate with peak flow meter.

Results: It showed significant difference when pre values were compared with outcome post measures like inspiratory capacity with incentive spirometer, peak expiratory flow rate with peak flow meter, and chest expansion using inch tape.

Conclusion: The present study concluded that Autogenic drainage of breathing control is effective for improving chest expansion, peak expiratory flow rate and inspiratory capacity in abdominal surgery patients.

Key Words: $A D$ - Abdominal surgeries - Incentive spirometer - Peak flow meter - Inch tape.

\section{Introduction}

POSTOPERATIVE pulmonary complications (PPC) present high rates of morbidity, mortality, increased hospital costs and prolonged hospital stay predominantly in abdominal surgery [1]. Surgery has become an important part of global health care, which is estimated to about 234 million patients operated yearly. Approximately $16 \%$ will

\section{Correspondence to: Dr. Faten A. Hamza,}

The Department Physical Therapy for CardiovascularRespiratory Disorders and Geriatrics, Faculty of Physical Therapy, Delta University for Science and Technology, Cairo, Egypt suffer a complication within 30 days [2]. Diseases affecting the abdominal cavity are generally treated under their own name (e.g. appendicitis). Surgeries of the abdominal organs are performed according to the description of that organ (stomach, kidney, liver, etc.) Most commonly performed abdominal surgeries are Appendectomy; exploratory laparotomy refers to the opening of the abdominal cavity and for the direct examination of its contents, for example, to locate a source of bleeding or trauma etc. and Laparoscopy is a minimally invasive procedure of the abdominal cavity where rigid [3] Upper abdominal surgical procedures are associated with a higher risk of complications more frequently than are lower abdominal surgeries [4,5]. The risk rates of postoperative pulmonary complications in upper abdominal surgery range from $17 \%$ to $88 \%$.

In addition, The Surgical Infection recommends that duration for complicated abdominal infections should be limited to 4-7 days, and may be discontinued sooner in the absence of clinical signs of infection [6]. Pulmonary complications are most common, and are defined as pulmonary abnormalities occurring in the post-operative period producing clinically significant identifiable disease and dysfunction that adversely affect the clinical course [7]. Surgery and general anesthesia directly affects the respiratory system. Surgeries alter postoperative pulmonary function, as observed by impairment of lungs volume such as total lung capacity, vital capacity and tidal volume. It also reduces the efficiency of efforts to cough for as long as one week and also fall in an oxygen arterial pressure and in oxygen-hemoglobin saturation [8] . Currently Pulmonary complications have significant impact on morbidity, mortality after major abdominal surgery [9] . Post-operative pulmonary complications (PPC'S) have been reported to occur in $5-10 \%$ of the general patient population and in $4-22 \%$ of patients who has undergone abdominal surgery 
[10]. According to some authors, surgery lasting for more than 210 minutes is a risk factor for postoperative pulmonary complications [11]. That found a lack of lung inflation, Prolong recumbent positioning, decrease cough effectiveness, increase risk associated with retained pulmonary secretions and change ventilation pattern. Patients operated with upper abdominal surgery (UAS) usually develop a restrictive lung pattern, with changes to pulmonary mechanics in the first post-operative days, leading to a high risk of developing pulmonary complications (PPCs) [12]. Atelectasis, pneumonia, trachea bronchitis, bronchospasm, exacerbation of chronic obstructive pulmonary disease, acute respiratory failure and prolonged mechanical ventilation (longer than 48 hours) can be classified as PPCs $[\mathbf{1 3 , 1 4}]$. The goals of chest physiotherapy are to improve ventilation-perfusion matching, increase lung volume, enhance mucociliary clearance, and decrease pain, When normal breath is inhaled, with or without a breath-hold of 1-3 seconds, followed by rapidly squeezing out air by contracting the chest wall and abdominal muscles with the mouth and glottis open. The huff should be active, but not a violent or explosive exhalation. Subsequent huffs may start at higher lung volumes (further into the inspiratory reserve volume) and again move into the expiratory reserve volume (but perhaps not as deep as the first mid-level huffs) [15] . Autogenic drainage (AD), an airway clearance technique (ACT) recognized by the International Physiotherapy [16]. That uses controlled breathing and minimal coughing to clear secretions from your chest. It involves hearing and feeling your secretions as you breathe out and controlling the desire to cough until secretions are high up and easily reached with minimal effort [16] . This technique has been shown to create sustained airflow that is higher than usual in the airways of the lungs which affects the lungs and together with pain from incision and stitches makes deep breathing and coughing difficult and thick mucus collected in patient's lungs. Autogenic Drainage has used session to exclude any pre-existing pulmonary and cardiac diaphragmatic breathing to mobilize secretions by varying conditions [17]. AD Will change lung volumes rather than using forced expiration to increase airflow velocity. The flow-volume curves when using AD, compared with forced expiration overlap; explaining how unforceful breathing during $\mathrm{AD}$ can remove secretions from the airways [18]. And is a system of breathing exercises to sequentially attend the highest possible expiratory flow to move secretions from peripheral to central airways without forced expirations and associated airway closure. It has three-phase breath- ing exercise. The gradually increasing Subjects and inspiratory and expiratory reserve volumes from functional residual capacity and a 2 to 3 second breath-holding period may have resulted in collateral filling among the alveoli and improved ventilation and mobilized secretions. For that at the end of the session the mucus was evacuated by stronger expiration or a high volume huff. During a huff, the pressure in the airway (intraluminal pressure) decreases from the peripheral airways to the mouth, because of frictional pressure loss and loss of convective acceleration pressure [19]Huffs may start at higher lung volumes (further into the inspiratory reserve volume) and again move into the expiratory reserve volume (but perhaps not as deep as the first midlevel huffs) [20].Autogenic Drainage was introduced by Chevaillier in Belgium in the year 1967 for the treatment of chronic obstructive pulmonary disease patients, Autogenic Drainage on quiet expirations in a relaxed state without the use of postural drainage positions. Autogenic Drainage has used session to exclude any pre-existing pulmonary and cardiac diaphragmatic breathing to mobilize secretions by varying conditions of expiratory airflow [21]. Confirm the results of this study; concerning that much of the work with autogenic drainage has been focused on patients with COPD should take into account its effects on lung volumes, expiratory flow, and dynamic airway compression. Care should be taken to avoid airway collapse during expirations in patients with reduced lung recoil pressure [22]

\section{Patients and Methods}

The study submits in Special Zaied Hospital, Thirty participants who underwent laparotomy with the age group of 30-60 years. The study extended from October 2017 to March 2018, were included according to inclusion and exclusion criteria in this study. The inclusion criteria for this study were both male and female participants, those who are willing to participate in this study, individuals who underwent elective and emergency laparotomy. And exclusion criteria for the study were unstable and complicated abdominal surgery patient's any pre-existing pulmonary and cardiac conditions. Patients with chronic respiratory disorders and age more than 65 years. The intervention was given once in a day, 7 days in a week for a period of 1 week. AD was given for around 10-15 minutes. Each treatment session lasted for 15-30 minutes including rest periods in between. Begin with some gentle relaxed breaths known as breathing control, First phase take a very slow deep breath in through your nose, to your absolute maximum possible. Pause at the end of the full 
breath with your mouth slightly open and count for 3-4 seconds. Start by sitting in a comfortable upright position. Second phase Breathe out through your mouth. This should be active (you can feel your tummy muscles tighten) but should not be forced. Third phase you should listen and feel for secretions crackling as you breathe out are the crackles at the beginning, middle or end of your breath out? Beginning=High up in large tubes of your chest Middle=In the middle sized tubes End $=$ In the small tubes. The intervention was given once in a day ( 7 sessions) for 1 week. Outcome measures Chest expansion measurement, it was measured with inch tape at Axillary level of the chest. Peak expiratory flow rate was measured by meter in L/minutes. Pre and post readings were taken before and after intervention of Incentive spirometer (Helios 401). Inspiratory capacity was measured using incentive spirometer. Pre and Post readings were taken before and after intervention.

\section{Results}

On comparison of pre and post intervention of $\mathrm{AD}$ using chest expansion and using paired $t$-test showed $t$-value 8.246 and $p$-value is $<0.0001$ is considered extremely significant. On comparison of pre and post intervention of AD using incentive spirometer and using paired $t$-test showed $t$-value 0.2444 and $p$-value is 0.8105 is considered not significant. On comparison of pre and post intervention of $\mathrm{AD}$ using peak flow meter and using paired $t$-test showed $t$-value 12.464 and $p$-value is $<0.0001$ is considered extremely significant.

Table (1): Pre and post comparison of chest expansion, incentive spirometer and PEFR.

\begin{tabular}{llllll}
\hline & \multirow{2}{*}{$\begin{array}{c}\text { Outcome } \\
\text { measures }\end{array}$} & \multicolumn{2}{c}{ Mean $\pm \mathrm{SD}$} & & \\
\cline { 3 - 4 } & \multicolumn{1}{c}{ Pre } & Post & & & \\
\hline Autogenic & Chest expansion & 0.484 & 1.547 & 8.246 & $<0.0001$ \\
drainage & Incentive spirometer & 4.838 & 5.014 & 0.244 & 0.8105 \\
& PEFR & 85.517 & 311.98 & 12.464 & $<0.0001$ \\
\hline
\end{tabular}

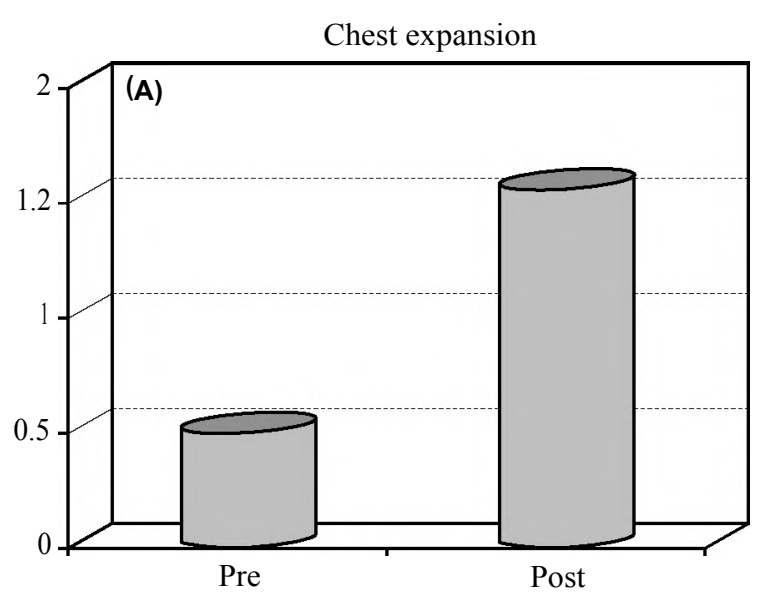

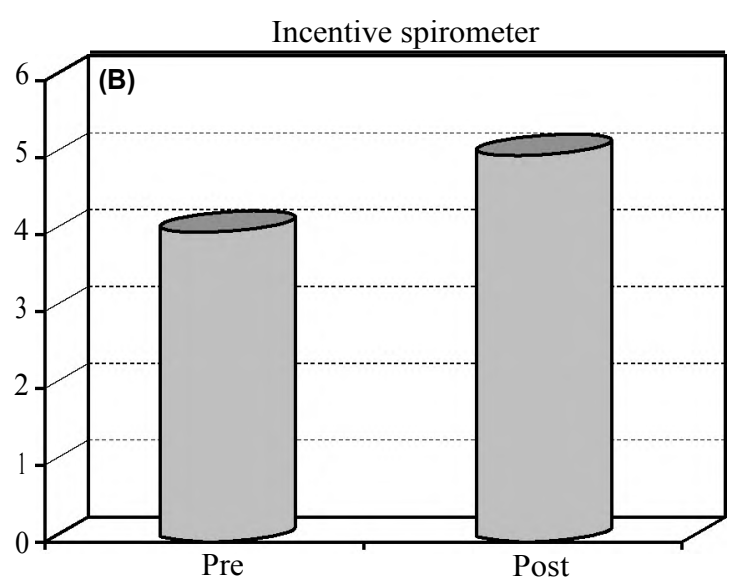

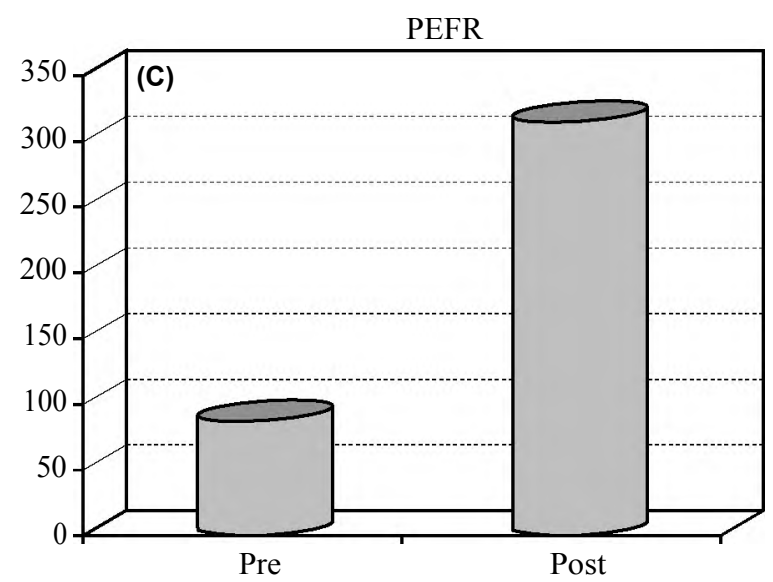

Fig. (1 A,B,C): Pre and post comparison of chest expansion, incentive spirometer and peer.

\section{Discussion}

In spite of many advancesin the case of the surgical patient, pulmonary problems continue to constitute the major post-operative complications. The study shows significant changes in chest expansion, peak expiratory flow rate and inspiratory capacity within a week of AD intervention after one week of intervention. Chest expansion Breathing exercises can lead to sustained increase in trans pulmonary pressure which helps to distend the lungs and re-inflates the collapsed lung segments, Thoracic expansion exercises re-expands the lung tissue and helps in mobilizing and clearing excess bronchial secretions which is explained by the phenomenon of interdependence [1]. It states that expanding forces exerts effective pressure that dilates the airways as Tran's pulmonary pressure and lung volume increases. Normal airways are maintained by this Trans pulmonary pressure. It counteracts airway compression during forced expiration. Interdependence has physiological and pathological significance. Weakening of these forces of interdependence leads to airway dysfunction and causes dysfunction of the airways [1]. In abdominal surgeries various changes occur in pulmonary function and respiratory mechanics, 
leading to post-operative pulmonary complication and leads to reduction in chest expansion. By using interventions like Autogenic Drainage (AD) there is gradual increase in inspiratory and expiratory reserve volumes from functional residual capacity and a 2 to 3 second breath-holding period. These results in collateral filling among the alveoli improved ventilation and mobilized secretions. This exercise decreases the atelectasis area and increase ventilation maintains expansion of lungs and prevents collapse due to which chest expansion was improved [11]. They found that Chest clearance techniques, autogenic drainage breathing in COPD patients with thirty subjects were selected within 40-60 years of age and who had moderate chronic obstructive pulmonary disorder is effective in clearance of secretions [1]. Spirometer measures maximal expiratory flow and exhaled volume during an expiratory vital capacity maneuver. According to previous studies on the test is widely available and is highly standardized in terms of performance, methodology, and equipment specifications [18]. Peak flow rate obtained as maximum instantaneous expiratory flow that is used as an indicator of airway caliber. Measurement of pulmonary functions can also checked by measuring the peak expiratory flow (PEF) [7]. In healthy lungs, the factors determining the Peak Expiratory Flow Rate are the expiratory muscle strength, especially the abdominals. The dimensions of the intra and the extra thoracic airways, the maximum alveolar pressure reaching speed and the ability of the lung to undergo elastic recoil [8]. That found associated compliance with Peak Expiratory Flow Monitoring in Home Management of Asthma. They concluded that short term compliance with PEF measurement is fairly good [13]. AD may help preserve lung function over the course of the disease, in keeping with current goals of CF disease management [27] The short-term studies showed that AD cleared a clinically significant amount of sputum in a single treatment session $[28]$

\section{Conclusion:}

The present study concluded that Autogenic drainage effective for improving chest expansion, peak expiratory flow rate and inspiratory capacity in abdominal surgery patients.

\section{References}

1- SMETANA G.W.: Postoperative pulmonary complications: An update on risk assessment and reduction. Cleve. Clin. J. Med., 76 Suppl., 4: S60-5, 2009.

2- KAZAURE H., ROMAN S. and SOSA J.: Association of post discharge complications with reoperation and mortality in general surgery. Arch. Surg., 147: 1000-7, 2012.
3- BROEK R., et al.: Burden of adhesions in abdominal and pelvic surgeries systemic review and met analysis. BMJ., 2013.

4- VALERIE L.D.R., et al.: Risk of Pulmonary Complications after Elective Abdominal Surgery, 1996.

5- CHEIFETZ O., DEBORAH L., et al.: The effect of abdominal support on functional outcomes in patients following major. Abdominal. Surgery, 2010.

6- ABDELAAL A. and ABDELAAL M.: Post-operative pulmonary complications. International Journal of Advanced Research, 2 (7): 784-801, 2014.

7- EMILY M., et al.: An Evaluation of peak expiratory flow monitoring: A comparison of sitting versus standing measurements. JABFM, 23 (2), 2010.

8- SITALAKSHMI R., et al.: The peak expiratory flow rate (PEFR): The effect of stress in a geriatric population of chennai. Clinical and Diagnostic Research, 7 (2): 409410, 2013.

9- SAVCI S., DENIZINAL M. and ARIKAN H.: A comparison of autogenic drainage and the active cycle of breathing techniques in patients with chronic obstructive pulmonary disease. Journal of Cardio Pulmonary Rehabilitation, 20 (1): 37-43, 2000.

10- BELLONE A,. LASCOLI R., RASCHI S., et al.: Chest physical therapy in patients with acute exacerbation of chronic bronchitis: Medicine and Rehabilitation, 81 (5): 558-60, 2000.

11- MELAM G.: Comparison of autogenic drainage \& active cycle breathing techniques on FEV1, FVC \& PEFR in chronic obstructive pulmonary disease. World Applied Sciences Journal, 20 (6): 818-822, 2012.

12- WANGE P., et al.: Incentive spirometry versus active cycle of breathing technique: Effect on chest expansion and flow rates in post abdominal surgery patients. International Journal of Research in Medical Sciences, 4 (11): 2016.

13- LAMUVEL M., et al.: Effect of ACBT and TENS on pulmonary function and pain perception in abdominal surgeries. A randomized control trial. Health Sciences and Research, 6 (6), 2016.

14- SOLOMKIN J. and MAZUSKI J.: Intra-abdominal sepsis newer interventional and antimicrobial therapies. Infect. Dis. Clin. North. Am., 23 (3): 593-608, 2009.

15- TIMOTHY M., TONG G., et al.: Enhançed recovery pathways for major abdominal surgeries ${ }^{2 n d}$ enhanced recovery after surgery (ERAS) USA Symposium held on in New Orleans Lousian, 10, 2014.

16- CELSO R., CARVALHO, DENISE M. PAISANI, et al.: Incentive spirometry in major surgeries: A systemic review. Rev. Bras. Fisioter., 15 (5): 343-345, 2011.

17- FINK J.: Forced expiratory technique, directed cough, and autogenic drainage. Respir. Care., 52 (9): 1210-1221, 2007.

18- MILLER M.R., HANKINSON J., BRUSASCO V., BUR GOS F., CASABURI R., COATES A., et al.: Standardisation of spirometry. Eur. Respir. J., 26: 319-338, 2005

19- BELLONE A., R. LASCOLI, S. RASCHI, L. GUZZI and R. ADONE: Chest physical therapy in patients with acute exacerbation of chronic bronchitis: Effectiveness of three 
methods. Archives of Physical Medicine and Rehabilitation, 81 (5): 558-60, 2000.

20- PONTIFEX E., WILLIAMS M.T., LUNN R. and PARSONS D.: The effect of huffing and directed coughing on energy expenditure in young asymptomatic subjects. Aust. J. Physiother, 48 (3): 209-213, 2002.

21- HOLLAND A.E. and BUTTON B.M.: Is there a role for airway clearance techniques in chronic obstructive pulmonary disease? Chron. Respir. Dis., 3 (2): 83-91, 2006.

22- International Physiotherapy Group for Cystic Fibrosis. Physiotherapy for people with cystic fibrosis: From infant to adult [Internet]. New York: The Group, Updated Cited 2013 Sep. 29, 2009.

23- HEMMES S., GAMA DE ABREU M., PELOSI P. and SCHULTZ M.J.: Prove network investigators for the clinical trial network of the European Society of Anesthesiology. High versus low positive end-expiratory pressure during general anesthesia for open abdominal surgery a multicenter randomized controlled trial. Lancet, 384 (9942): 495-503, 2014.

24- MCILWAINE M., CHILVERS M., LEE SON N., et al. Analysis of expiratory flow rates used in autogenic drainage. Are they sufficiently high to mobilize secretions? J. Cyst. Fibros., 13 (2): S29, 2014.
25- JOEHL R.: Preoperative evaluation: Pulmonary, cardiac, renal dysfunction and comorbidities. Surg. Clin. North. Am., 85 (6): 1061-7, 2005.

26- SMETANA G.: Postoperative pulmonary complications: an update on risk assessment and reduction. Cleve. Clin. J. Med., 76 (4): S60-5, 2009.

27- SCHIDLOW D.V.: Maintaining the horizontal line, early intervention and prevention of CF lung disease. J. Cyst. Fibros., 3 (2): 63-6, 2004.

28- PFLEGER A., THEISSL B., OBERWALDNER B., et al.: Self-administered chest physiotherapy in cystic fibrosis: a comparative study of high-pressure PEP and autogenic drainage. Lung., 170 (6): 323-30, 1992.

29- PONTIFEX E., WILLIAMS M.T., LUNN R. and PARSONS D.: The effect of huffing and directed coughing on energy expenditure in young asymptomatic subjects. Aust. J. Physiother., 48 (3): 209-213, 2002.

30- RESTREPO R., WETTSTEIN R., WITTNEBEL L. and TRACY M.: Incentive spirometry: Respir. Care., 56 (10): 1600-04, 2011.

31- ARRUDA K., CATANEO D. and CATANEO A.: Surgical risk tests related to cardiopulmonary postoperative complications: Comparison between upper abdominal and thoracic surgery. Acta. Cirurgica. Brasileira., 28 (6): 45866, 2013.

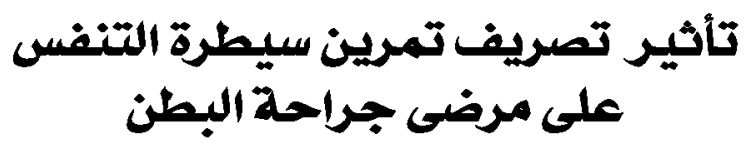

\footnotetext{
الهدف من الدراسة: تقييم تأثير تقنية تصريف تمرين سيطرة التنفس على مرضس جراحة البطن.

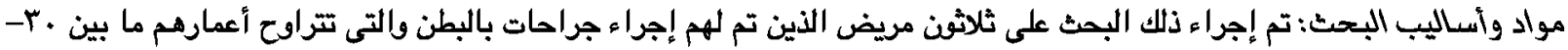

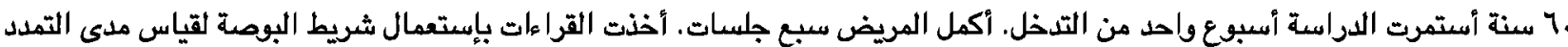

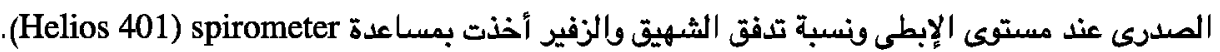

النتائج: أستنجت الدراسة الحالية بأن تصريف تمرين سيطرة التفس فعال لتحسين توبسع الصدر، وزيادة نسبة تدفق الشهيق والزفير في مرضى جراحة البطنى.

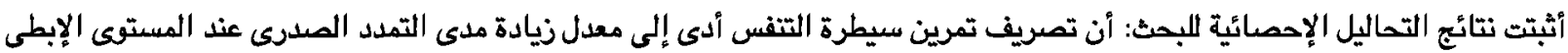

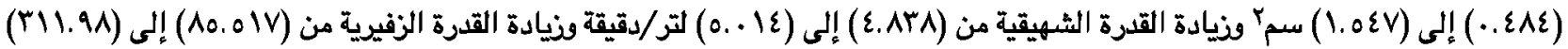

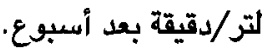

الملخص: أستنتج الدرامة الحالية بأن تصريف تمرين سيطرة التنفس فعال لتحسين توبس الصدر، يزيد من نسبة تدفق زفيرية وقدرة الثهيق فى مرضى جراحة البطن.
} 